\title{
The Characteristics, Values and Importance of Leading Talents in the Hospital Innovation Team
}

\author{
Baiyi Wang, Shan Bao, Min Guo $\mathbb{\circledR}^{\text {, }}$, Zhixiang Chen, Yu Lin, Changwang Luo, Fei Li, Shengshi Lu \\ Hainan General Hospital, Haikou, China \\ Email: g2002m@163.com
}

How to cite this paper: Wang, B.Y., Bao, S., Guo, M., Chen, Z.X., Lin, Y., Luo, C.W., Li, F. and Lu, S.S. (2021) The Characteristics, Values and Importance of Leading Talents in the Hospital Innovation Team. Open Journal of Preventive Medicine, 11, 55-62.

https://doi.org/10.4236/ojpm.2021.112005

Received: January 4, 2021

Accepted: February 17, 2021

Published: February 20, 2021

Copyright $\odot 2021$ by author(s) and Scientific Research Publishing Inc. This work is licensed under the Creative Commons Attribution International License (CC BY 4.0).

http://creativecommons.org/licenses/by/4.0/

\begin{abstract}
Leading talents and innovation team are the key to build an innovative hospital. It is necessary and practical to recognize the importance, characteristics and value of leading talents and innovative teams. This paper summarizes some characteristics, values and importance of leading talents and innovative teams in China's General hospitals (General hospitals with complete medical specialties and advanced equipment) for reference.
\end{abstract}

\section{Keywords}

Hospital, Leading Talents, Innovation Team, Innovation-Oriented Hospital

\section{Introduction}

China attaches great importance to the work of talents, puts the task of strengthening the awareness of talents in the first place, and proposes to establish a strong awareness of talents. At present, the excavation and utilization of talents focuses on the development of innovative talents, is fundamentally to build an institutional system, and the key is to improve the level of party management talents. To rely on national major talent training plans, major scientific research and major projects, key disciplines and key scientific research base, international academic exchange and cooperation projects, promoting innovation team building, cultivating a batch of having both ability and political integrity, international first-class technology top talents, master of international science and technology talents [1], and building innovative hospital, talent and the team are the key, and the most important key is to have to take the lead, with discipline talents and highly creative innovation team. In this paper, the main relationship and characteristics between "leading talents" and "innovation team" are summa- 
rized as follows.

\section{The Urgency of Scientific and Technological Innovation Drives the Innovation Team}

\subsection{Urgency of China's Scientific and Technological Innovation}

Under the lead and promote the of science and technology, human beings are experiencing from the evolution of the industrial society to knowledge society, science and technology constantly create new economic growth point, in solving a series of major issues for the sustainable development of human is playing an increasingly important role, become the basic driving force of economic and social development and human form the main source of wealth. In the context of globalization, scientific and technological competition has increasingly become the focus of national competition, and independent scientific and technological innovation has become the decisive factor of national competitiveness. In view of the general trend of the current development of science and technology economy, all the major countries in the world have made basically the same strategic choice, regarding science and technology innovation as the national strategy. The U.S. government regards keeping the United States in the forefront of scientific knowledge as a national strategic goal. The UK government has set out the need to ensure that the science base is excellent and strong, and to put innovation at the heart of productivity and economic growth. The Japanese government has successively put forward the national strategies of establishing the country through scientific and technological innovation and intellectual property rights. The Korean government proposes that it is necessary to formulate and implement policies based on science and technology at the national level in order to explore new paths for national development. At present, developed countries gain competitive advantage by recruiting talents and controlling intellectual property rights all over the world. According to statistics, $40 \%$ of the world's skilled immigrants attract to the United States, of which 70\% come from developing countries [2]. Due to the lack of independent innovation capacity, developing countries are faced with increasingly serious problems of economic security, national defense security and cultural security. In the face of this situation, late-developing countries can not only take advantage of the historical opportunity of scientific and technological revolution to realize the leap of social productivity, but also may widen the development gap with advanced countries and finally be marginalized.

\subsection{The Important Role of Innovation Teams in Scientific and Technological Innovation}

Only technological innovation can achieve leapfrog development in scientific research projects, and technological innovation is often a collective innovation [3]. With the development of science and technology, the specialization division and the intensification of competition, it is difficult to realize new scientific dis- 
coveries and significant progress only by individual soldiers and simple cooperation. Team tackling has become the internal requirement of science and technology research activities under the production conditions of modern society, and team has become the main form of organization operation. According to the survey, since the 1980s, teams have emerged in large numbers in American enterprise organizations. More than $70 \%$ of the organizations have more than one team, while IBM, GE and other large companies have more than one team. It has as many as 100 teams [4]. A team is a small group of people who work in isolation and hold themselves accountable to each other. They have common goals, performance goals, and working methods. Innovation team is a special working group, which is based on scientific and technological research and development. It is composed of a few researchers with complementary skills who are willing to take responsibility for the common scientific research purposes, scientific research objectives and working methods. Scientific and technological innovation teams can produce positive synergies through the joint efforts of their members, making the team's performance level far higher than the sum of the performances of several individual members. The innovation team is of great significance to the promotion and promotion of national scientific and technological competitiveness.

\section{The Leader Is the Key Factor for the Formation and Development of Innovation Team}

Ernest Rutherford is a world famous scientist. He won the Nobel Prize in chemistry in 1908 and is regarded as the father of nuclear physics. The Cavendish laboratory in Cambridge, he served as director of 18 years, for his excellence in scientific research organization ability and scientific thinking, make the laboratory in modern scientific research fruits, and trained a large number of outstanding achievements in their respective research field of scientists, including Nobel prizewinners reached 13 people, these achievements and Rutherford as the leading talents in the Cavendish laboratory role is inseparable [5]. In addition to the joint efforts of each member, a high performance team must have a leading talent. That is, leading talent or general talent. Only division commanders, commanders and soldiers are unable to fight a major battle. Only the commander and marshal of a corps can organize and command successful campaigns and operations. The role of a team leader can be coach, teacher, or monitor. He should be able to inspire his teammates, impart experience to them, solve their problems, and convince them. When necessary, he should jump down to fight by himself. It is the biggest challenge for team leaders to make capable and willing people follow the supervisor wholeheartedly, motivate capable and unwilling members, and promote willing and incompetent members. Leading talents often play a decisive role in scientific and technological innovation. The spirit temperament, personality charm and enterprise of leading talents all have a decisive influence on the team. He is the soul of a team. Leading talents can decide $80 \%$ of the fate of a team [6]. They can turn their efforts into joint forces, 
implement and execute team goals, keep team members sensitive to external reactions and make quick responses, and meanwhile, find good ways and methods for team operation. He is good at doing things with collective power and creating value with "integration". One or two leading talents often determine the international status of a research team or even a country in this field. Whoever has the first-class talents with the latest technology can have an advantage in the technological competition. Therefore, the leading talents are compared to the "handsome talent" in the army and the "head lion" in the pride of lions. When we emphasize teamwork and innovation, we should never neglect the role and value of team leaders.

\section{Value of Leading Talents in the Innovation Team}

\subsection{Value of Leading Talents as Technological Innovators in the Innovation Team}

In hospital innovation teams, technical innovators are often the leaders. Technological innovation is inseparable from human beings, which needs human capital integrated with human knowledge and ability. The role of human capital in enterprise technological innovation is positive and positive [7]. Technical innovator is the inventor of the core technology, the owner or occupant, so technology innovators are different from ordinary workers or technicians, technical innovators are have excellent human resources, human capital in a very important position in the team: technical innovator is the source of the core technology team. Ignoring the creators of technological innovation results, the team will lack the lasting power of enterprise technological innovation, which will frustrate the innovation enthusiasm of technological innovator. The technical innovator is the core resource of the team. Team resources are generally divided into human, financial, material, technical, information, knowledge, etc., or further divided into natural resources, capital (physical and monetary), human resources, information resources (knowledge, intelligence, technology, management experience, brand, etc.). The role of technology innovators is critical. Technical innovator is an important component of team human capital. Managers and technical innovators are at the heart of team human capital. The existence of technological innovator as a form of human capital is determined by its core resource status. In the process of innovation, people's knowledge is constantly accumulated and enriched, and the stock of human capital is improved.

\subsection{The Value of Leading Talents as Expert Leaders in the Innovation Team}

Incompetent managers are the killers of a team. With the development of knowledge economy, technical experts are becoming the managers of teams. Research shows that team leadership is significantly related to team performance, and leadership is one of the key factors affecting team performance [8]. Most leaders of innovation teams come from technical experts. The characteristics of such 
expert leaders are as follows [9]:

1) Mastering the core technology of the team and be the technical authority in the team. Technology is at the heart of expert leadership's influence. Although it is impossible for technical leaders to maintain their leadership effect, almost all expert leaders rely on technology to establish their leadership position.

2) Pursuing logical analysis and rational decision making. The level and value of technical achievements can be evaluated objectively. The education and training of expert leaders determine that they pursue rigorous systematic analysis and rational decision-making and tend to pursue perfection and standard answers.

3) Emphasizing efficiency and quantitative management. The rigorous thinking of expert leaders enables them to be good at analysis and reasoning. They are good at subdividing and quantifying goals and tasks, making work schedules, doing rigorous work, and handling every detail carefully. According to the theory of leadership, the influence of leadership can be divided into two types: coercive influence and natural influence. Natural influence comes from the leader's own expertise, character, and charisma. The inherent characteristics of expert leaders determine that their influence is mainly manifested as natural influence [10]. First of all, as the technical authority of the team, the professional skills of expert leaders tend to drive knowledge workers to learn new technologies in a more positive attitude. Secondly, the rigorous work style of expert leaders and their ability to make logical analysis and rational decisions will also guide knowledge employees and set an example for them, thus forming an atmosphere of rigorous thinking and analysis within the team. Third, team members tend to admire experts in a particular field. And spontaneously align themselves with the leadership. Build team cohesion. Finally, the cultivation and personality charm of expert leaders will also be attractive to team members. The expert leader must adapt from the mentality and action, and become a real manager, not a technical expert engaged in management work. Expert leaders should give play to their personal charm as experts and scholars, build a culture suitable for their own team, establish leadership prestige and image, and enhance the cohesion of knowledge team. In this way, the success of the team can be guaranteed, the knowledge staff can be managed well, and the productivity of the knowledge team can be improved.

In recent ten years, a kind of ordered weighted average (OWA) operator for aggregating decision information [11], proposed by the famous American scholar Yager, has been widely used in the science of multi-attribute decision making [12]. The evaluation of talent quality is a kind of multi-attribute decision making activity, which is embodied in selecting the best plan from a group of limited alternatives.

\section{The Characteristics of Leading Talents}

As the leading talents, they should not only have their own talents, but also have 
the excellent qualities such as lofty value pursuit, outstanding scientific accomplishment, outstanding leadership, unique personality charm, tenacious fighting perseverance, strong team cohesion and extensive social influence. Its basic characteristics are as follows [13]:

1) "planner" and "schemer": the leading talents, under the same conditions, can see far and wide than others, can see the direction in a complex environment, control the overall situation, explore more opportunities and successfully use them.

2) "shaper" and "evangelist": The biggest role of leading talents is to cultivate or spread a culture or spirit, so that the whole team has the same idea, common goal and common code of conduct.

3 ) is always the courage and passion of the people: leading talent must be able to face adversity, despair, and do not give up. A successful leader should not only convince others with professional competence, but also know how to create a common vision and motivate members.

4) the person who stands behind the team: the leading talent realizes its role through "leading the military force" and team ability. On the surface, he is a representative talent, but in fact, it is the strength of the team that plays its role through the work of many positions and leaders at many levels.

\section{Shaping the General Model of Leading Talents}

Lack of strategic leading talents is a prominent problem facing the development of science and technology in China. If a dynamic and creative team doesn't have a good leader, no ideal can be realized. Generally speaking, there are four criteria to be followed as a leading talent:

1) Have a strong dedication, can put the overall situation as the most important, no matter how short or how long;

2) high ideological realm, can withstand praise, not because of a bit of success and complacent;

3) have a self-knowledge, see others strengths and shortcomings, can accept criticism and self-criticism;

4) good at summary, diligent in thinking, and strive to find out the rules.

The general requirements for shaping leading talents are as follows [13]:

1) train their ability to accept knowledge, so that they have a strong ambition, strong, dare to do, dare to take risks, can control the overall situation in a complex environment, as a planner or strategist;

2) cultivate their ability to analyze and summarize problems, make them willing to accept new knowledge and study hard, and cultivate or spread team culture;

3) cultivate their ability to judge problems, make them sensitive to things, foresee results, have the power to see through to the end, and be a person standing behind the team;

4) to cultivate their ability to change jobs and the ability to investigate and re- 
search. Make them self-aware. Don't think too highly of themselves. Always be aware of where the team and the individuals are.

To sum up, under the lead and promotion of science and technology, human beings are experiencing from the evolution of the industrial society to knowledge society. Science and technology constantly create new economic growth point, in solving a series of major issues for the sustainable development of human that is playing an increasingly important role, becoming the basic driving force of economic and social development, and human forms the main source of wealth. Scientific and technological innovation cannot be separated from excellent innovation teams, and excellent innovation teams cannot be separated from outstanding leading talents. Only by attaching importance to the innovation team and leading talents, can we take the road of independent innovation with Chinese characteristics, improve the competitiveness of the hospital to the greatest extent, and better realize the grand goal of building an innovative hospital.

\section{Conflicts of Interest}

The authors declare no conflicts of interest regarding the publication of this paper.

\section{Foundation Project}

Hainan Health Commission Science and Technology Project (No. 20A200441).

\section{References}

[1] Liu, Z.H. (2006) Medical Talent. Tsinghua University Press, Beijing, 56-58.

[2] Li, W.J. (2011) A Study on the Application of High Level Talents in the Affiliated Hospitals of Universities. Human Resource Management, No. 4, 170-172.

[3] Luan, Z.P., Huo, H., Gu, H.S., et al. (2016) Analysis on Dynamic Changes of Pharmaceutical Human Resources in a Regional Military Hospital. Journal of Pharmaceutical Practice, 34, 278-282.

[4] Sun, X.M., Zhou, X.H., Jing, L.M., et al. (2015) Exploration on the Construction and Reform of Rural Health Personnel Team in Pudong New Area of Shanghai. Chinese Journal of Hospital Management, 31, 362-364.

[5] Huang, R.X. (2006) A Study on the Relationship between the Degree of Satisfaction and the Degree of Satisfaction of Medical Professionals. China Hospital Management, 26, 32-33.

[6] Zhang, Y. (2017) Chestnut Aggregates. A Brief Analysis on the Current Situation and Countermeasures of Hospital Human Resource Management. Value Engineering, 36, 242-243.

[7] Chen, H.Z. (2016) Analysis on the Current Situation and Countermeasures of Hospital Human Resource Management. Management Observation, No. 27, 106-108.

[8] Kong, L.N. (2016) Research on the Current Situation and Countermeasures of Hospital Human Resource Management. Human Resource Management, No. 11, 187-188.

[9] Ren, X.J. and Feng, D. (2015) Research on the Cooperation Mechanism of Medical Talents in Beijing, Tianjin and Hebei. Cooperative Economy and Science and Technology, 11, 185-186. 
[10] Deng, F. (2011) Research on Influencing Factors of The Cultivation of Interdisciplinary Talents in Universities Based on the Integration of Production, Study and Research. Science and Technology Entrepreneurship Monthly, 25, 125-127.

[11] Yager, R.R. (1988) On Ordered Weight Averaging Aggregation Operators in Multicriteria Decision-Making. IEEE Transactions on Systems, Man, and Cybernetics, 18, 183-190. https://doi.org/10.1109/21.87068

[12] Filer, D. and Yager, R.R. (1998) On the Issue of Obtaining OWA Operator Weight. Fuzzy Sets and Systems, 94, 157-169. https://doi.org/10.1016/S0165-0114(96)00254-0

[13] Tang, M. (2015) Practical Exploration of the Management Mode of Introducing Excellent Medical Talents in Our Hospital. Chinese Hospital Management, 35, 51-52. 